WellBeing International

WBI Studies Repository

$9-2004$

\title{
Wild Justice and Fair Play: Cooperation, Forgiveness, and Morality in Animals
}

Marc Bekoff

University of Colorado

Follow this and additional works at: https://www.wellbeingintlstudiesrepository.org/acwp_ena

Part of the Animal Studies Commons, Behavior and Ethology Commons, and the Comparative Psychology Commons

\section{Recommended Citation}

Bekoff, M. (2004). Wild justice and fair play: Cooperation, forgiveness, and morality in animals. Biology and Philosophy, 19(4), 489-520.

This material is brought to you for free and open access by WellBeing International. It has been accepted for inclusion by an authorized administrator of the WBI Studies Repository. For more information, please contact wbisr-info@wellbeingintl.org.

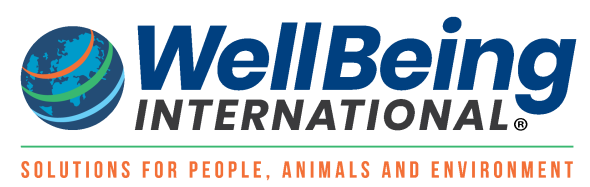




\title{
Wild Justice and Fair Play: Cooperation, Forgiveness, and Morality in Animals
}

\author{
Marc Bekoff \\ University of Colorado
}

\section{KEYWORDS}

anthropomorphism, cooperation, evolution of social behavior, fairness, forgiveness, prediction, social contract, social morality, social play, trust

\section{ABSTRACT}

In this paper I argue that we can learn much about 'wild justice' and the evolutionary origins of social morality - behaving fairly - by studying social play behavior in group-living animals, and that interdisciplinary cooperation will help immensely. In our efforts to learn more about the evolution of morality we need to broaden our comparative research to include animals other than non-human primates. If one is a good Darwinian, it is premature to claim that only humans can be empathic and moral beings. By asking the question 'What is it like to be another animal?' we can discover rules of engagement that guide animals in their social encounters. When I study dogs, for example, I try to be a 'dogocentrist' and practice 'dogomorphism.' My major arguments center on the following 'big' questions: Can animals be moral beings or do they merely act as if they are? What are the evolutionary roots of cooperation, fairness, trust, forgiveness, and morality? What do animals do when they engage in social play? How do animals negotiate agreements to cooperate, to forgive, to behave fairly, to develop trust? Can animals forgive? Why cooperate and play fairly? Why did play evolve as it has? Does 'being fair' mean being more fit - do individual variations in play influence an individual's reproductive fitness, are more virtuous individuals more fit than less virtuous individuals? What is the taxonomic distribution of cognitive skills and emotional capacities necessary for individuals to be able to behave fairly, to empathize, to behave morally? Can we use information about moral behavior in animals to help us understand ourselves? I conclude that there is strong selection for cooperative fair play in which individuals establish and maintain a social contract to play because there are mutual benefits when individuals adopt this strategy and group stability may be also be fostered. Numerous mechanisms have evolved to facilitate the initiation and maintenance of social play to keep others engaged, so that agreeing to play fairly and the resulting benefits of doing so can be readily achieved. I also claim that the ability to make accurate predictions about what an individual is likely to do in a given social situation is a useful litmus test for explaining what might be happening in an individual's brain during social encounters, and that intentional or representational explanations are often important for making these predictions.

Wild justice: social morality, manners, and cooperation in animals

Those communities which included the greatest number of the most sympathetic members would flourish best and rear the greatest number of offspring. (Charles Darwin 1871/1936, p. 163) 
I believe that at the most fundamental level our nature is compassionate, and that cooperation, not conflict, lies at the heart of the basic principles that govern our human existence...By living a way of life that expresses our basic goodness, we fulfill our humanity and give our actions dignity, worth, and meaning. (His Holiness The Dalai Lama 2002, p. 68)

Different as they are from language-using human beings, they are able to form relationships not only with members of their own species, but also with human beings, while giving expression to their own intentions and purposes. So that the relationships are far more clearly analogous to human relationships than some of the philosophical theorizing that I have discussed would allow. Some human beings indeed and some nonhuman animals pursue their respective goods in company with and in cooperation with each other. And what we mean by 'goods' in saying this is precisely the same, whether we are speaking of human or dolphin or gorilla. (Macintyre 1999, p. 61)

Now he worships at an altar of a stagnant pool; And when he sees his reflection, he's fulfilled; Oh, man is opposed to fair play; He wants it all and he wants it his way. (Bob Dylan 1983).

The behavior of non-human animal beings ('animals') fascinates people of all ages and of all cultures. People around the world are interested in what animals do, either because they are interested in the animals themselves or because they want to know more about the origins of human behavior. There also is much interdisciplinary interest in questions about animal behavior - what available data mean, what methods are the best for answering questions that are frequently at once important, challenging and frustrating, and what role do representatives of each discipline play in helping us to gain a better understanding of the behavior of our non-human kin. Interdisciplinary discourse is essential. I also want to stress that all sorts of information including anecdotes, intuitions, philosophical musings, and 'hard' data, are important as we try to understand 'wild justice' and the origins of moral behavior (Allen, this volume, argues that there are many levels of abstraction that inform explanations of animal behavior). 'Real world' examples - data from careful studies of animal behavior - are critical for furthering our understanding. Anecdotes, intuitions, and philosophical musings along with empirical data all drive further empirical research. I also want to emphasize the importance of adopting a broad comparative approach to the study of animal behavior and for coming to terms with what available information has to say about the cognitive abilities of other animals in the context of what we know about them in terms of their own evolutionary and natural histories.

Of course some people want to learn more about animals to make the case for human uniqueness, usually claiming that humans are 'above' and 'better' than other animals. But the more we study animals and the more we learn about 'them' and 'us' we frequently discover there is not a real dichotomy or nonnegotiable gap between animals and humans because humans are, of course, animals. There is evolutionary continuity. Art, culture, language, and tool use and manufacture can no longer be used to separate 'them' from 'us' (but perhaps cooking food is uniquely human; Wrangham and Conklin-Brittain 2003). Line-drawing can be very misleading especially when people take the view that non-human animals are 'lower' or 'less valuable' than 'higher' animals, where 'higher' means human. In many ways 'we are them' and 'they are us' (Bekoff 2002a).

Darwin $(1859,1872 / 1998)$ emphasized that there is evolutionary continuity among different species. His ideas about evolutionary continuity, that behavioral, cognitive, emotional, and moral variations among different species are differences in degree rather than differences in kind, are often invoked in trying to answer questions about the evolution of various behavioral phenotypes. On this view there are shades of 
gray among different animals and between nonhumans and humans, that the differences are not black and white with no transitional stages or inexplicable jumps (Gruen 2002; Güzeldere and Nahmias 2002; see also many other essays in Bekoff et al. 2002). Current work in evolutionary biology and anthropology suggests that linear scales of evolution in which there are large gaps between humans and at least some animals are simplistic views of the evolutionary process.

There is no doubt that we can learn much about humans by carefully studying our animal kin and also by listening to their stories. One reason I find the study of animal behavior, and in particular questions centering on animal cognition, animal emotions, and animal morality to be so fascinating, exciting, and also frustrating and challenging, is because I want to learn more about why both the similarities and differences have evolved.

One area that will surely benefit from a meeting of interdisciplinary minds concerns the evolution of social morality and the negotiation and maintenance of cooperation, fairness, kindness, generosity, trust, respect, and social norms. Researchers from many disciplines have debated the evolutionary origins of social morality, asking if some animals have codes of social conduct that regulate their behavior in terms of what is permissible and what is not permissible during social encounters (for wide ranging discussion see Kropotkin 1902; Solomon 1995; de Waal 1996, 2001; Hurd 1996; Ridley 1996, 2001; Mitchell 1998; Macintyre 1999; Sober and Wilson 1998, 2000; Journal of Consciousness Studies, Volume 7, No. 1/2, 2000; Field 2001; Hinde 2002; Jamieson 2002; Wilson 2002; de Waal and Tyack 2003). These scientists and philosophers want to know what are the moral capacities of animals, can they be moral agents with a moral sense who are able to live in moral communities? In a recent issue of the Journal of Consciousness Studies (Volume 7, No. 1/2, 2000) researchers from many disciplines debated the evolutionary origins of morality. These scholars were interested in discussing animal roots on which human morality might be built, even if human morality is not identical to animal morality, which it likely is not.

Recently there also has been a resurgence of interest in the notion of fairness and altruism in humans (Sober and Wilson 1998, 2000; Douglas 2001; Riolo et al. 2001; Sigmund and Nowak 2001; Bowles and Gintis 2002; Fehr and Gächter 2002; Jamieson 2002; Sigmund et al. 2002; Bewley 2003; Fehr and Rockenbach 2003). Researchers are interested in learning about how individuals from different cultures share resources, and if they share them equitably even if they are not compelled to do so. Despite Bob Dylan's lament (above) much research shows that human beings are more generous and more fair than game-theory and other models predict. There seems to be a set of core values that are learned through social interactions with others, and these values influence moral decisions. There also is evidence that people will punish free-riders in the absence of personal gain, and that cooperation is sustained by such 'altruistic punishment' (Bowles and Gintis 2002; Fehr and Gächter 2002). Taken together, cross-cultural data suggest that there may be an innate drive to be fair. Of course, much more comparative work still needs to be done.

But what about animals? Can there be 'wild justice?' Is 'being fair, nice, and moral' doing what comes naturally? I will return to these questions below. Charles Darwin argued this case and also considered the development and the intellectual and moral faculties that are important in cooperative social encounters.

Many animals live in fairly stable social groups that resemble those of ancestral humans. There are divisions of labor, food sharing, communal care of young, and inter- and intrasexual dominance hierarchies. Many animals, especially mammals, also share with humans neuroanatomical structures in the amygdala and hypothalamus and neurochemicals (dopamine, serotonin, oxytocin) that form the neural bases for the expression and experience of emotions and empathy (Panksepp 1998; Preston and de Waal 2002). A wide variety of social behavior patterns in animals have also been influenced by living in groups of various sizes. If one is a good Darwinian and believes in evolutionary continuity, it seems 
premature to claim that only humans can be empathic and moral beings. As we increasingly come to recognize that animals share their emotions with us it becomes increasingly difficult to deny their existence.

\section{Social play: a foundation of fairness}

In this essay I consider various aspects of the evolution of cooperation and fairness using social play behavior in animals, especially mammals, as my exemplar of an activity in which one would expect to see on-going negotiations of cooperation and agreements to behave fairly because the social dynamics of play require that players agree to play and not to fight or to mate with one another. I am specifically concerned with the notion of 'behaving fairly.' I touch on many topics that are considered elsewhere in this volume, including what is cognitive ethology, anthropomorphism, the importance of broadening our taxonomic horizons in studies of animal cognition beyond non-human primates, levels of selection, and the role that anecdotes, intuitions, and common sense play in doing 'hard' science, and generating data that may be called 'science sense' (Bekoff 2002a).

By 'behaving fairly' I use as a working guide the notion that animals often have social expectations when they engage in various sorts of social encounters the violation of which constitutes being treated unfairly. By studying the details and dynamics of social play behavior one can test some of these ideas. Also tied into the notion of expectation is the element of surprise. Often, animals seem surprised by what happens to them in a given social interaction. For example, a dog or wolf may cock her head from side-to-side and squint, as if she is wondering what went 'wrong' when a play-mate becomes too assertive or too aggressive. Perhaps they feel indignant when they are wronged, when their expectations or sense of justice is violated, when they feel they are not being treated 'right.'

I will conclude that social play is a 'foundation of fairness.' I argue that it is through social cooperation that groups (communities) are built from individuals agreeing to work in harmony with other individuals. Further, based on recent research on the neurobiology of human cooperation, I argue that 'being fair' may feel good for animals as well. Lastly, I stress that in our efforts to learn more about the evolution of social morality we need to broaden our comparative research to include animals other than non-human primates.

\section{The science of cognitive ethology: naturalizing the study of animal minds}

There are two kind of biologists: those who are looking to see if there is one thing that can be understood, and those who keep saying it is very complicated and nothing can be understood. (Pigliucci 2002, p. 92)

Colin Allen (this volume) wants to know 'Is anyone a cognitive ethologist?' I think I am but I will let you decide after you read his essay in this volume. Basically, the interdisciplinary science of cognitive ethology is concerned with claims about the evolution of cognitive processes. Since behavioral abilities have evolved in response to natural selection pressures, ethologists favor observations and experiments on animals in conditions that are as close as possible to the natural environment where selection occurred. Often a double-standard is used to criticize cognitive ethology for being too 'soft.' For example, levels of statistical significance and data bases that are acceptable in other branches of science are not accepted in cognitive ethological studies (Griffin 2001; Bekoff 2002a). Why is this so? Reasons offered include lack of control of observations and experiments and also the fact that mental experiences are private affairs and hypotheses about mental experiences are not falsifiable. I have little to say about this other than that it is clear that cognitive ethology is a field of science, that we have the tools to learn much about mental processes and mental states in animals, and that falsifiable hypotheses can be offered and 
tested (Allen and Bekoff 1997; Griffin 2001; Bekoff 2002a; Bekoff Allen and Burghardt 2002). We also now really do now know quite a lot about animal minds (Hauser 2000; Griffin 2001; Bekoff 2002a; essays in (Bekoff, Allen and Burghardt 2002). Skeptics need to offer more motivated reasons for bashing cognitive ethology. (It is important to note that the atmosphere at the meeting at which the papers in this volume were presented was very pro-animal cognition. Nonetheless, critical and skeptical questions were asked but the discussion did not get bogged down nor was it deflected by an insistence that the lack of absolute certainty means that no or little progress can be made on the questions at hand. I will return to this topic later on in my brief discussion of the notion of prediction.)

No longer constrained by psychological behaviorism, cognitive ethologists are interested in comparing thought processes, consciousness, beliefs, and rationality in animals. In addition to situating the study of animal cognition in a comparative and evolutionary framework, cognitive ethologists also argue that field studies of animals that include careful observation and experimentation can inform studies of animal cognition, and that cognitive ethology will not have to be brought into the laboratory to make it respectable (Allen and Bekoff 1997). Furthermore, because cognitive ethology is a comparative science, cognitive ethological studies emphasize broad taxonomic comparisons and do not focus on a few select representatives of limited taxa. Cognitive psychologists, in contrast to cognitive ethologists, usually work on related topics in laboratory settings, and do not emphasize comparative or evolutionary aspects of animal cognition. When cognitive psychologists do make cross-species comparisons, they are typically interested in explaining different behavior patterns in terms of common underlying mechanisms. Ethologists, in common with other biologists, are often more concerned with the diversity of solutions that living organisms have found for common problems.

Many different types of research fall under the term 'cognitive ethology' and it is pointless to try to delimit the boundaries of cognitive ethology; because of the enormous amount of interdisciplinary interest in the area, narrow definitions of cognitive ethology are likely to become rapidly obsolete. There also seems to be little difference between methods used to study animal cognition and those used to study other aspects of animal behavior. Differences lie not so much in what is done and how it is done, but rather how data are explained. Colin Allen and I, in our book, Species of mind: The Philosophy and biology of cognitive ethology (1997), have argued that the main distinction between cognitive ethology and classical ethology lies not in the types of data collected, but in the understanding of the conceptual resources that are appropriate for explaining those data.

\section{Classical ethology and cognitive ethology: what is it like to be a___?}

Nobel Laureate Niko Tinbergen (1963) identified four overlapping areas with which ethological investigations should be concerned, namely, evolution (phylogeny), adaptation (function), causation, and development (ontogeny). Tinbergen's framework is also useful for those interested in animal cognition (Jamieson and Bekoff 1993; Allen and Bekoff 1997; Smuts 2001). Burghardt (1997) suggested adding a fifth area, private experience. He (p. 276) noted that 'The fifth aim is nothing less than a deliberate attempt to understand the private experience, including the perceptual world and mental states, of other organisms. The term private experience is advanced as a preferred label that is most inclusive of the full range of phenomena that have been identified without prejudging any particular theoretical or methodological approach.'

Burghardt's suggestion invites what he calls 'critical anthropomorphism,' carefully used anthropomorphism, an approach with which many agree. I have suggested that we be 'biocentrically anthropomorphic' and that by doing so we do not necessarily lose the animal's point of view. We are humans and we have by necessity a human view of the world (Bekoff 2000b; see also Keeley's and Allen's essays in this volume). 
The way we describe and explain the behavior of other animals is influenced and limited by the language we use to talk about things in general. By engaging in anthropomorphism we make the world of other animals accessible to ourselves and to other human beings. By being anthropomorphic we can more readily understand and explain the emotions or feelings of other animals. But this is not to say that other animals are happy or sad in the same ways in which humans (or even other members of the same species) are happy or sad. Of course, I cannot be absolutely certain that my late dog, Jethro, was happy, sad, angry, upset, or in love, but these words serve to explain what he might have been feeling. Merely referring to the firing of different neurons or to the activity of different muscles in the absence of behavioral information and context is insufficiently informative because we do not know about the specific situation in which the animal finds herself.

\section{Being a dog-o-centrist}

My research and that of others begins with the question 'What is it like to be a specific animal?' So, when I study dogs, for example, I try to be a dog-o-centrist and practice dogomorphism. Thus, when I claim that a dog is happy, for example when playing, I am saying it is dog-joy, and that dog-joy may be different from chimpanzee-joy. While I will not go into it any further, this is a very important stance for it stresses that there are important species and individual differences in behavior, cognitive capacities, and emotions, and that it is wrong and simplistic to claim that if animal joy is not like our joy then they do not have it.

What it basically comes down to is that as humans studying other animals, we cannot totally lose our anthropocentric perspective. But we can try as hard as possible to combine the animals' viewpoints to the ways in which we study, describe, interpret, and explain their behavior.

\section{The evolution of social morality: continuity, proto-morality, and questions of human uniqueness}

Evolutionary reconstructions of social behavior often depend on educated guesses (some better than others) about the past social (and other) environments in which ancestral beings lived. In the same sense that other's minds are private, so is evolution (Bekoff 2002a). Often it is difficult to know with a great deal of certainty very much about these variables and how they may have figured into evolutionary scenarios. It is an understatement to note that is extremely difficult to study the evolution of morality in any animal species, and the very notion of animal morality itself often makes for heated discussions. Bernstein (2000) claims that 'morality in animals might lie outside of the realm of measurement techniques available to science' (p. 34). Nonetheless, it seems clear that detailed comparative analyses of social behavior in animals can indeed provide insights into the evolution of social morality. Certainly, these sorts of studies are extremely challenging, but the knowledge gained is essential in our efforts to learn more about the evolution of sociality and social morality and to learn more about human nature and perhaps human uniqueness.

Many discussions of the evolution of morality center on the development of various sorts of models (e.g. Axelrod 1984; Ridley 1996, 2001; Skyrms 1996; Dugatkin 1997; Sober and Wilson 1998, 2000; essays in Journal of Consciousness Studies, 2000, volume 7, No. 1/2). While these models are very useful for stimulating discussion and further research, they do not substitute for available data (however few) that may bear on animal morality (see, for example, some essays in Aureli and de Waal (2000) for additional comparative information and also Dugatkin and Bekoff (2003).

The study of the evolution of morality, specifically cooperation and fairness, is closely linked to science, religion, theology, spirituality and perhaps even different notions of God, in that ideas about continuity and discontinuity (the possible uniqueness of humans and other species), individuality, and freedom need to 
be considered in detail. Furthermore, it is important to discuss relationships among science, religion, and God because spirituality and the notion of one form of God or another had strong influences on the evolution of our ancestors, their cognitive, emotional, and moral lives.

Peterson (2000; see also Peterson 1999) has discussed the evolutionary roots of morality (stages that he refers to as 'quasi-morality' and 'proto-morality' in animals) and religion in relation to the roles played by cognition and culture. He also stresses the importance of recognizing continuities and discontinuities with other animals, arguing ultimately (and speciesistically) that while some animals might possess protomorality (they are able 'to rationally deliberate actions and their consequences', p. 475) none other than humans is 'genuinely moral' because to be able to be genuinely moral requires higher emergent levels of cognition as well as culture and the world view that culture provides, namely, religion. Peterson (2000, $p$. 478) claims that 'Quasi-moral and protomoral systems do not require a global framework that guides decision making. They are always proximate and pragmatic. In these systems, there is no long-term goal or ideal state to be achieved. Yet, genuine morality is virtually inconceivable without such conceptions.'

Peterson also claims that any sociobiological account (based on selfishness or combativeness) of human morality is incomplete. I agree and also argue that this is so for some non-human animals as well. When animals are studied in their own worlds they may indeed have their own form of genuine morality, there might indeed be long-term goals and ideal states to be achieved. Our anthropocentric view of other animals, in which humans are so taken with themselves, is far too narrow. The worlds and lives of other animals are not identical to those of humans and may vary from species-to-species and even within species. The same problems arise in the study of emotions (Bekoff 2000a, 2002a, 2004) if we believe that emotions in animals are going to be identical to or even recognizably similar among different species. There is also variability among humans in what some might view as long-term goals and ideal states, and it would be premature to conclude that there is one set of long-term goals and ideal states that characterize, or are essential to, the capacity to be genuinely moral. To cash out stages of moral evolution as does Peterson, it looks like quasi-morality and proto-morality are less than genuine morality.

\section{Cooperation and fairness are not by-products of aggression and selfishness}

...my thesis is that justice is first of all a natural sentiment, an inborn sense of our connectedness with others and our shared interests and concerns. (Solomon 1995, $p$. 153)

My arguments center on the view that cooperation is not merely always a byproduct of tempering aggressive and selfish tendencies (combating Richard Dawkins' (1976) selfish genes) and attempts at reconciliation. Rather, cooperation and fairness can evolve on their own because they are important in the formation and maintenance of social relationships (Solomon 1995 also forcefully argues this point). This view contrasts with those who see aggression, cheating, selfishness, and perhaps amorality as driving the evolution of sociality, fairness, and justice. The combative Hobbesian world in which individuals are constantly at one another's throat is not the natural state of affairs. Nature is not always red in tooth and claw,. Dawkins (2001) himself has been quoted as saying 'A pretty good definition of the kind of society in which I don't want to live is a society founded on the principles of Darwinism.'

\section{Does it feel good to be fair?}

It will be only after we have established the facts of mutual aid in different classes of animals and their importance for evolution, that we shall be able to study what belongs in the evolution of sociable feelings, to parental feelings, and what to sociability proper... Mutual Aid [is] an argument in favor of a pre-human origin of moral instincts, but 
also as a law of Nature and a factor of evolution. (Petr Kropotkin 1902, pp. x-xii) Justice begins with our emotional engagement in the world, not in philosophical detachment or in any merely hypothetical situation. (Solomon 1995, 199)

Studies of the evolution of social morality need to pay close attention to the rich cognitive, intellectual, and deep emotional lives of animals (Bekoff 2000a,b, 2002a,b) and how these capacities figure into moral sensibility and the ability to make moral judgments. Truth be told, we really do not know much about these capacities even in our primate relatives despite claims that we do (Bekoff 2002c, 2003a, 2005). We know that animals and humans share many of the same emotions and same chemicals that play a role in the experience and expressions of emotions such as joy and pleasure. If being nice feels good then that is a good reason for being nice. It is also a good reason for a pattern of behavior to evolve and to remain in an animal's arsenal.

Are some animals capable of the emotions and empathy that might underlie morality? We know that in humans the amygdala and hypothalamus are important in emotional experiences and that they are mediated by neurotransmitters such as dopamine, serotonin and oxytocin. We also know that many animals, especially mammals, share with humans the same neurological structures and chemicals (Panksepp 1998; Bekoff 2002a). Of course, this does not necessarily mean animals share our feelings, but careful observation of individuals during social encounters suggests that at least some of them do. While their feelings are not necessarily identical to ours this is of little or no concern because it is unlikely that they should be the same as ours.

Empathy is also important to consider. Preston and de Waal (2002) argue that empathy is more widespread among animals than has previously been recognized (see also Kuczaj et al. 2001). In a classic study, Wechlin et al. (1964) showed that a hungry rhesus monkey would not take food if doing so subjected another monkey to an electric shock. In similar situations rats will also restrain themselves when they know their actions would cause pain to another individual (Church 1959). In another study, Diana monkeys were trained to insert a token into a slot to obtain food (Markowitz 1982). A male was observed helping the oldest female who had failed to learn the task. On three occasions he picked up the tokens she had dropped, put them into the machine, and allowed her to have the food. His behavior seemed to have no benefits for him at all; there did not seem to be any hidden agenda.

Along these lines, de Waal observed Kuni, a captive female bonobo, capture a starling and take the bird outside and place it on its feet (Preston and de Waal 2002). When the bird did not move Kuni tossed it in the air. When the starling did not fly Kuni took it to the highest point in her enclosure, carefully unfolded its wings and threw it in the air. The starling still did not fly and Kuni then guarded and protected it from a curious juvenile.

Elephants also may show concern for others. Poole (1998), who has studied African elephants for decades, was told a story about a teenage female who was suffering from a withered leg on which she could put no weight. When a young male from another group began attacking the injured female, a large adult female chased the attacking male, returned to the young female, and touched her crippled leg with her trunk. Poole argues that the adult female was showing empathy and sympathy.

While good stories alone are not enough to make a compelling argument, when there are many such anecdotes they can be used to provide a solid basis for further detailed empirical research. Ignoring them is to ignore a rich data base. I have argued elsewhere that 'the plural of anecdote is data' (Bekoff 2002a).

We will probably never know whether these rats, monkeys, and elephants were feeling empathy as we do. But there are ways in which we can begin comparing what is going on in animal brains to what 
happens in our own. Neuroimaging techniques are shedding new light on human emotions, and it likely will not be long before we begin doing similar studies with other animals.

It is important to consider the possibility that it feels good to be fair to others, to cooperate with them and to treat them fairly, to forgive them for their mistakes and shortcomings. Recent neural imaging research on humans by Rilling and his colleagues (Rilling et al. 2002) has shown that the brain's pleasure centers are strongly activated when people cooperate with one another, that we might be wired to be fair or nice to one another. (I do not want to argue here that 'being fair' always means 'being nice.') This is extremely significant research for it posits that there is a strong neural basis for human cooperation and that it feels good to cooperate, that being nice is rewarding in social interactions and might be a stimulus for fostering cooperation and fairness. Despite challenging technical difficulties, this sort of non-invasive research is just what is needed on other animals.

\section{Animal play and social contracts: Lessons in cooperation, justice, fairness, and trust}

What is justice? Justice is fairness, so they say. But, what is fair? (Bradie 1999, p. 607)

Happiness is never better exhibited than by young animals, such as puppies, kittens, lambs, \& c., when playing together, like our own children. So wrote Charles Darwin in The Descent of Man and Selection in Relation to Sex (Darwin 1871/1936, p. 448).

Animal play is obvious and few if any people would argue that play is not an important category of behavior (for definitions of social play see Bekoff and Byers 1981, 1998; Fagen 1981; Power 2000; Burghardt 2005). Animal social morality, however, is a more slippery concept. Cognitive ethological approaches are useful for gaining an understanding of social play for various reasons including (Allen and Bekoff 1997): (1) it exemplifies many of the theoretical issues faced by cognitive ethologists; (2) empirical research on social play has and will benefit from a cognitive approach, because play involves communication, intention, role-playing, and cooperation; (3) detailed analyses of social play may provide more promising evidence of animal minds than research in many other areas, for it may yield clues about the ability of animals to understand one another's intentions; and (4) play occurs in a wide range of mammalian species and in a number of avian species, and thus it affords the opportunity for a comparative investigation of cognitive abilities extending beyond the narrow focus on primates that often dominates discussions of nonhuman cognition. For example, during social play, many animals engage in self-handicapping and role-reversals, two behavior patterns that are often used to make inferences about intentionality (and consciousness and self-consciousness).

Social play in animals is an exhilarating activity in which to engage and to observe. The rhythm, dance, and spirit of animals at play is incredibly contagious. Not only do their animal friends want to join in or find others with whom to romp, but I also want to play when I see animals chasing one another, playing hideand-seek, and wresting with reckless abandon. My body once tingled with delight as I watched a young elk in Rocky Mountain National Park, Colorado, running across a snow field, jumping in the air and twisting his body while in flight, stopping to catch his breath, and then jumping and twisting over and over and again. There was plenty of grassy terrain around but he chose the more challenging snow field in which to romp (supporting Byers' $(1977,1998)$ idea that play may be very important in physical training). Buffaloes will also follow one another and playfully run onto and slide across ice, excitedly bellowing 'Gwaaa' as they do so. And, of course, we all know that dogs and cats love to play, as do many other mammals. I and many others have observed birds also playfully soar across the sky chasing, diving here and there, and frolicking with one another. 
Consider also some of my field notes of two dogs at play:

Jethro bounds towards Zeke, stops immediately in front of him, crouches on his forelimbs, wags his tail, barks, and immediately lunges at him, bites his scruff and shakes his head rapidly from side-to-side, works his way around to his backside and mounts him, jumps off, does a rapid bow, lunges at his side and slams him with his hips, leaps up and bites his neck, and runs away. Zeke takes wild pursuit of Jethro and leaps on his back and bites his muzzle and then his scruff, and shakes his head rapidly from side-to-side. Suki bounds in and chases Jethro and Zeke and they all wrestle with one another. They part for a few minutes. sniffing here and there and resting. Then, Jethro walks slowly over to Zeke, extends his paw toward Zeke's head, and nips at his ears. Zeke gets up and jumps on Jethro's back, bites him, and grasps him around his waist. They then fall to the ground and mouth wrestle. Then they chase one another and roll over and play. Suki decides to jump in and the three of them frolic until they're exhausted. Never did their play escalate into aggression.

The unmistakable emotions associated with play - joy and happiness - drive animals into becoming at one with the activity. One way to get animals (including humans) to do something is to make it fun, and there is no doubt that animals enjoy playing. Studies of the chemistry of play support the claim that play is fun. Dopamine (and perhaps serotonin and norepinephrine) are important in the regulation of play. Rats show an increase in dopamine activity when anticipating the opportunity to play (Siviy 1998) and enjoy being playfully tickled (Panksepp 1998; 2000). There is also a close association between opiates and play (Panksepp 1998).

Neurobiological data are essential for learning more about whether play truly is a subjectively pleasurable activity for animals as it seems to be for humans. Siviy's and Panksepp's findings suggest that it is. In light of these neurobiological ('hard') data concerning possible neurochemical bases for various moods, in this case joy and pleasure, skeptics who claim that animals do not feel emotions might be more likely to accept the idea that enjoyment could well be a motivator for play behavior.

\section{It begins with a 'bow': 'I want to play with you'}

To learn about the dynamics of play it is essential to pay attention to subtle details that are otherwise lost in superficial analyses. During play there are continuous rapid exchanges of information 'on the run.' Dogs and other animals keep track of what is happening when they play so we also need to pay attention to details. My studies of play are based on careful observation and analyses - some might say obsessive analyses - of video-tape. I watch tapes of play one frame at a time to see what the animals are doing and how they exchange information about their intentions and desires to play. This is tedious work and some of my students who were excited about studying dog play had second thoughts after watching the same video frames over and over again. But when they then were able to go out and watch dogs play and understand what was happening they came to appreciate that while studying play can be hard work it's well-worth the effort.

So, a typical scene might go as follows. 'Would you care to play' asks one wolf of another? 'Yes, I would' says the other. After each individual agrees to play and not to fight, prey on, or mate with the other, there are on-going rapid and subtle exchanges of information so that their cooperative agreement can be finetuned and negotiated on the run, so that the activity remains playful. Incorporated into many explanations of social play are such notions as making a deal, trusting, behaving fairly, forgiving, apologizing, and perhaps justice, behavioral attributes that underlie social morality and moral agency (Bekoff 2002a). 
Recent research by Okamoto and Matsumara (2001) suggests that punishment and apology play a role in maintaining cooperation between individual non-human primates.

When individuals play they typically use action patterns that are also used in other contexts, such as predatory behavior, antipredatory behavior, and mating activities. Behavior patterns that are observed in mating may be intermixed in flexible kaleidoscopic sequences with actions that are used during fighting, looking for prey, and avoiding being eaten. These actions may not vary much across different contexts, or they may be hard to discriminate even for the participants. So, how do animals know that they are playing? How do they communicate their desires or intentions to play or to continue to play? How is the play mood maintained?

Because there is a chance that various behavior patterns that are performed during on-going social play can be misinterpreted, individuals need to tell others 'I want to play,' 'this is still play no matter what I am going to do to you,' or 'this is still play regardless of what I just did to you.' An agreement to play, rather than to fight, mate, or engage in predatory activities, can be negotiated in various ways. Individuals may use various behavior patterns - play markers - to initiate play or to maintain (prevent termination of) a play mood (Bekoff 1975, 1977a, 1995; Bekoff and Allen 1992, 1998; Allen and Bekoff 1997; lack, Jeannotte, and de Waal 2004) by punctuating play sequences with these actions when it is likely that a particular behavior may have been, or will be, misinterpreted (it is also possible that there are auditory, olfactory, and tactile play markers; Bekoff and Byers 1981; Fagen 1981).

One action that is very common in play among canids (members of the dog family) is the 'bow.' Bows occur almost exclusively in the context of social play. The 'bow,' a highly ritualized and stereotyped movement that seems to function to stimulate recipients to engage (or to continue to engage) in social play, has been extensively studied in various canids in this context. Bows (the animal crouches on her forelimbs and elevates her hindlimbs) occur throughout play sequences, but most commonly at the beginning or towards the middle of playful encounters. In a detailed analysis of the form and duration of play bows (Bekoff 1977a) I discovered that duration was more variable than form, and that play bows were always less variable when performed at the beginning, rather than in the middle of, ongoing play sequences. Three possible explanations for this change in variability include: (1) fatigue, (2) the fact that animals are performing them from a wide variety of preceding postures, and (3) there is less of a need to communicate that 'this is still play' than there is when trying to initiate a new interaction. These explanations are not exclusive alternatives.

In a long-term and continuing study of social play I also found that play signals in infant canids (domestic dogs, wolves, and coyotes) were used non-randomly, especially when biting accompanied by rapid sideto-side shaking of the head was performed (Bekoff 1995). Biting accompanied by rapid side-to-side shaking of the head is performed during serious aggressive and predatory encounters and can easily be misinterpreted if its meaning is not modified by a play signal. Following the work of Bateson (2000); Neuman (2003, p. 1) argues that in certain situations such as play 'meaning is a form of coordination between interacting agents, and that this form of coordination is orchestrated through context markers...' He refers to this process as 'meaning-in-context.'

Play signals are an example of what ethologists call 'honest signals.' There is little evidence that social play is a manipulative or 'Machiavellian' activity. Play signals are rarely used to deceive others in canids or other species. There are no studies of which I am aware that actually look at the relative frequencies of occurrence of honest and deceptive play signaling, but my own long-term observations indicate that deceptive signaling is so rare that I cannot remember more than a few occurrences in thousands of play sequences. Cheaters are unlikely to be chosen as play partners because others can simply refuse to play with them and choose others. Limited data on infant coyotes show that cheaters have difficulty getting 
other young coyotes to play (personal observations). It is not known if individuals select play partners based on what they have observed during play by others.

In domestic dogs there is little tolerance for non-cooperative cheaters. Cheaters may be avoided or chased from play groups. There seems to be a sense of what is right, wrong, and fair. While studying dog play on a beach in San Diego, California, Horowitz 2002) observed a dog she called Up-ears enter into a play group and interrupt the play of two other dogs, Blackie and Roxy. Up-ears was chased out of the group and when she returned Blackie and Roxy stopped playing and looked off toward a distant sound. Roxy began moving in the direction of the sound and Up-ears ran off following their line of sight. Roxy and Blackie immediately began playing once again. Even in rats fairness and trust are important in the dynamics of playful interactions. Pellis (2002), a psychologist at the University of Lethbridge in Canada, discovered that sequences of rat play consist of individuals assessing and monitoring one another and then fine-tuning and changing their own behavior to maintain the play mood. When the rules of play are violated, when fairness breaks down, so does play.

Detailed analyses show that individual actions may change their form and duration during play. Individuals might also know that they are playing because the actions that are performed differ when they are performed during play when compared to other contexts (Hill and Bekoff 1977), or the order in which motor patterns are performed differs from, and might be more variable than, the order in which they are performed during the performance of, for example, serious aggressive, predatory, or reproductive activities (Bekoff and Byers 1981).

Individuals also engage in role-reversing and self-handicapping (Bekoff and Allen 1998; Bauer and Smuts 2002; Horowitz 2002) to maintain social play. Each can serve to reduce asymmetries between the interacting animals and foster the reciprocity that is needed for play to occur. Self-handicapping happens when an individual performs a behavior patterns that might compromise herself. For example, a coyote might not bite her play partner as hard as she can, or she might not play as vigorously as she can. Watson and Croft (1996) found that red-neck wallabies adjusted their play to the age of their partner. When a partner was younger, the older animal adopted a defensive, flat-footed posture, and pawing rather than sparring occurred. In addition, the older player was more tolerant of its partners tactics and took the initiative in prolonging interactions.

Role-reversing occurs when a dominant animal performs an action during play that would not normally occur during real aggression. For example, a dominant animal might voluntarily not roll-over on his back during fighting, but would do so while playing. In some instances role-reversing and self-handicapping might occur together. For example, a dominant individual might roll over while playing with a subordinate animal and inhibit the intensity of a bite.

From a functional perspective, self-handicapping and role-reversing, similar to using specific play invitation signals and gestures, or altering behavioral sequences, might serve to signal an individual's intention to continue to play. In this way there can be mutual benefits to each individual player because of their agreeing to play and not fight or mate. This might differentiate cooperative play from the situation described above in which a male Diana's monkey helped a female get food when she could not learn the task that would bring her food. There seemed to be no benefit to the male to do so. (I thank Jan Nystrom for marking this distinction.)

\section{Can animals forgive?}

Even for the behavior of forgiving, which is often attributed solely to humans, the renowned evolutionary biologist David Sloan Wilson (2002) shows that forgiveness is a complex biological adaptation. In his 
book Darwin's cathedral: Evolution, religion, and the nature of society, Wilson concludes that '.. forgiveness has a biological foundation that extends throughout the animal kingdom.' (p. 195) And further, '... Forgiveness has many faces - and needs to - in order to function adaptively in so many different contexts.' (p. 212) While Wilson concentrates mainly on human societies his views can easily be extended - and responsibly so - to non-human animals. Indeed, Wilson points out that adaptive traits such as forgiveness might not require as much brain power as once thought. This is not to say that animals aren't smart but rather that forgiveness might be a trait that is basic to many animals even if they don't have especially big and active brains. Perhaps if we try to learn more about forgiveness in animals and how it functions in play we will also learn to live more compassionately and cooperatively with one another.

\section{Fine-tuning play: why cooperate and play fairly?}

Why do animals carefully use play signals to tell others that they really want to play and not try to dominate them, why do they engage in self-handicapping and role-reversing? Why do they plan play? During social play, while individuals are having fun in a relatively safe environment, they learn ground rules that are acceptable to others - how hard they can bite, how roughly they can interact - and how to resolve conflicts. There is a premium on playing fairly and trusting others to do so as well. There are codes of social conduct that regulate actions that are and are not permissible, and the existence of these codes likely speak to the evolution of social morality. What could be a better atmosphere in which to learn social skills than during social play, where there are few penalties for transgressions? Individuals might also generalize codes of conduct learned in playing with specific individuals to other group members and to other situations such as sharing food, defending resources, grooming, and giving care. (Social morality does not mean other animals are behaving unfairly when they kill for food, for example, for they have evolved to do this.)

Playtime generally is safe time. Transgressions and mistakes are forgiven and apologies are accepted by others especially when one player is a youngster who is not yet a competitor for social status, food, or mates. There is a certain innocence or ingenuousness in play. Individuals must cooperate with one another when they play - they must negotiate agreements to play (Bekoff 1995). Fagen (1993, p. 192) noted that 'Levels of cooperation in play of juvenile primates may exceed those predicted by simple evolutionary arguments...' The highly cooperative nature of play has evolved in many other species (Fagen 1981; Bekoff 1995; Bekoff and Allen 1998; Power 2000; Drea and Frank 2003; Burghardt 2005). Detailed studies of play in various species indicate that individuals trust others to maintain the rules of the game (Bekoff and Byers 1998). While there have been numerous discussions of cooperative behavior in animals (e.g. Axelrod 1984; deWaal 1996; Ridley 1996; Dugatkin 1997; Hauser 2000; essays in Journal of Consciousness Studies, Volume 7, No. 1/2, 2000 and references therein), none has considered the details of social play, the requirement for cooperation and reciprocity and its possible role in the evolution of social morality, namely behaving fairly.

Individuals of different species seem to fine-tune on-going play sequences to maintain a play mood and to prevent play from escalating into real aggression. Detailed analyses of film show that in canids there are subtle and fleeting movements and rapid exchanges of eye contact that suggest that players are exchanging information on the run, from moment-to-moment, to make certain everything is all right, that this is still play. Aldis (1975) suggested that in play, there is a 50:50 rule so that each player 'wins' about $50 \%$ of their play bouts by adjusting their behavior to accomplish this (for further discussion and details on rodent play, see Pellis 2002).

Why might animals fine-tune play? Why might they try hard to share one another's intentions? While play in most species does not take up much time and energy (Bekoff and Byers, 1998; Power 2000), and in 
some species only minimal amounts of social play during short windows of time early in development are necessary to produce socialized individuals (two 20 min play sessions with another dog, twice a week, are sufficient for domestic dogs from 3 to 7 weeks of age (Scott and Fuller 1965)), researchers agree that play is very important in social, cognitive, and/or physical development, and may also be important for training youngsters for unexpected circumstances (Spinka, Newberry, and Bekoff 2001). While there are few data concerning the actual benefits of social play in terms of survival and reproductive success, it generally is assumed that short-term and long-terms functions (benefits) vary from species-to-species and among different age groups and between the sexes within a species. No matter what the functions of play may be, there seems to be little doubt that play has some benefits and that the absence of play can have devastating effects on social development (Power 2000; Spinka, Newberry, and Bekoff 2001; Burghardt 2005).

During early development there is a small time window when individuals can play without being responsible for their own well-being. This time period is generally referred to as the 'socialization period' for this is when species-typical social skills are learned most rapidly. It is important for individuals to engage in at least some play. All individuals need to play and there is a premium for playing fairly if one is to be able to play at all. If individuals do not play fairly they may not be able to find willing play partners. In coyotes, for example, youngsters are hesitant to play with an individual who does not play fairly or with an individual who they fear (Bekoff 1977b). In many species individuals also show play partner preferences and it is possible that these preferences are based on the trust that individuals place in one another.

\section{Fairness and fitness: coyotes, play, and dispersal}

One big question of interest to biologists is how differences in the performance of a given behavior influences an individual's reproductive success. It is extremely difficult to show with great certainty that the performance of a specific behavior is directly and causally coupled to reproductive success, especially under field conditions, so in many instances we have to rely on guesswork.

With respect to the topic at hand the question is 'Do differences in play and variations in fair play influence an individual's reproductive fitness?' I am not arguing that there is a gene for social morality but I am claiming that it is reasonable to ask if there are differences among individuals and that perhaps more virtuous individuals are more fit and have more offspring than less virtuous individuals. A sense of fairness is common to many animals, and without it social play would be difficult to maintain. And without social play I and others have argued individual animals and entire groups would be at a disadvantage (Bekoff 2002a). If I am correct, morality evolved because it is adaptive in its own right not because it is merely an antidote to competition or aggression. Behaving fairly helps many animals, including humans, to survive and flourish in their particular social environment. I fully realize that this may sound like a radical idea, particularly if one views morality as uniquely human (and a sort of puzzling capacity) that sets us apart from other animals. But if you accept my argument that play and fairness may be linked then we need to demonstrate that individual animals might benefit from these behaviors.

Dogs, coyotes, and wolves are fast learners when it comes to fair play and I bet that other animals are as well. There are serious sanctions when they breach the trust of their friends and these penalties might indeed become public information if others see an individual cheating his companions. Biologists call these penalties 'costs,' which means that an individual might suffer some decline in his or her reproductive fitness if they do not play by the expected and accepted rules of the game.

My fieldwork on coyotes has revealed one direct cost paid by animals who fail to engage in fair play or who do not play much at all. I found that coyote pups who do not play as much as others because they are avoided by others or because they themselves avoid others are less tightly bonded to other members 
of their group and more likely to strike out on their own (Bekoff 1977b). But life outside the group is much more risky than within it. In a seven year study of coyotes living in the Grand Teton National Park outside Moose, Wyoming, we found that more than $55 \%$ of yearlings who drifted away from their social group died, whereas fewer than $20 \%$ of their stay-at-home peers did (Bekoff and Wells 1986). Was it because of play? We are not sure, but information that we collected on captive coyotes suggested that the lack of play was a major factor in individuals spending more time alone, away from their littermates and other group members.

\section{The evolution of fairness: a game-theoretical model}

Much research on the evolution of cooperation has been modeled using game-theoretic approaches. Dugatkin and Bekoff (2003) used a similar technique to analyze four possible strategies that an individual could adopt over time (for species in which fairness can be expressed during two different developmental stages), namely, being fair ( $F$ ) and at a later date being fair ( $F / F)$, being fair and then not fair ( $F / N F)$, being not fair and then fair (NF/F), and being not fair and then not fair (NF/NF). Of these, only F/F was an Evolutionarily Stable Strategy (ESS) that could evolve under the conditions of the model. None of the other three strategies were ESSs, and when no strategy was an ESS all four could coexist. There are two clear predictions from our results. First, always acting fairly should be more common than never acting fairly in species in which fairness can be expressed during two different developmental stages. Second, there should be many more cases in which none of the strategies we modeled would be an ESS, but all four could coexist at significant frequencies. That F/NF is not an ESS is of interest because this strategy could be conceived as a form of deceit. This finding fits in well with what is known about play signals, for as I mentioned above, there is little evidence that play signals are used to deceive others at any stage of development (Bekoff 1977a; Bekoff and Allen 1998). Our ideas are certainly testable in principle by following identified individuals and recording how they distribute fairness across different activities as they mature.

\section{Neurobiological bases of sharing intentions and mind-reading: possible connections among acting, seeing, feeling, and feeling/knowing}

Detailed observations and descriptions are mandatory. We need to know what animals are doing when they interact with one another in order to learn more about the neural correlates of their social activities. This work is tedious and time-consuming.

How might a play bow (or other action) serve to provide information to its recipient about the sender's intentions? Is there a relationship acting, feeling, seeing, and feeling/knowing? Perhaps one's own experiences with play can promote learning about the intentions of others. Perhaps the recipient shares the intentions (beliefs, desires) of the sender based on the recipient's own prior experiences of situations in which she performed play bows. Recent research suggests a neurobiological basis for sharing intentions. 'Mirror neurons,' found in macaques, fire when a monkey executes an action and also when the monkey observes the same action performed by another monkey (Gallese 1998; Gallese and Goldman 1998; Motluk 2001).

Research on mirror neurons is truly exciting and the results of these efforts will be very helpful for answering questions about which species of animals may have 'theories of mind' or 'cognitive empathy' about the mental and emotional states of others. Gallese and Goldman (1998) suggest that mirror neurons might 'enable an organism to detect certain mental states of observed conspecifics... as part of, or a precursor to, a more general mindreading ability.' Laurie Carr and her colleagues at The University of California at Los Angeles, discovered, by using neuroimaging in humans, similar patterns of neural activation both when an individual observed a facial expression depicting an emotion and when they 
imitated the facial expression. This research suggests a neurobiological underpinning of empathy (Laurie Carr, personal communication). Frith and Frith (1999) report the results of neural imaging studies in humans that suggest a neural basis for one form of 'social intelligence,' understanding others' mental states (mental state attribution).

More comparative data are needed to determine if mirror neurons (or functional equivalents) are found in other taxa and if they might actually play a role in the sharing of intentions or feelings - perhaps keys to empathy - between individuals engaged in an on-going social interaction such as play. Neuroimaging studies will also be especially useful.

\section{Levels of selection}

I am sure that close scrutiny of social animals will reveal more evidence that having a sense of fairness benefits individuals. More controversially, I also believe that a moral sense benefits groups as a whole because during social play group members learn rules of engagement that influence their decisions about what is acceptable behavior when dealing with each other. Such an understanding is essential if individuals are to work in harmony to create a successful group able to out compete other groups. Following the lines of Sober and Wilson's (1998, pp. 135ff) discussion concerning the choice of social partners, it may be that behaving fairly is a group adaptation, but once a social norm evolves it becomes individually advantageous to behave fairly for there are costs to not doing so (Elliott Sober, personal communication). We still need somehow to figure out how to test rigorously ideas about levels of selection - group selection 'versus' individual selection - and studies of the evolution of social morality are good places to focus for expanding our views (e.g. Boehm 1999; Leigh 1999; see also Aviles 1999; Bradley 1999; Gould and Lloyd 1999; Kitchen and Packer 1999; Mayr 2000).

\section{The importance of prediction: a litmus test for knowing?}

At the meeting at which this paper was presented I ended my talk making some general comments about the notion of prediction and how the ability to make accurate predictions about what an individual is likely to do in a given social situation may be closely linked with one's having extensive experience with those individuals. Of course, extensive formal ('scientific') experience watching animals is not necessary for being able to make accurate predictions. Also, while I cannot know with absolute certainty that any of the animals about whom I have written (or others) have beliefs, desires, or intentions, I also cannot know with absolute certainty if they have a sense of 'right' or 'wrong' or if they are merely acting 'as if' they are moral beings. They perform what can be called 'moral behavior' but it might have no bearing on what they are thinking or feeling. However, the inescapable uncertainty associated with these claims does not mean that I do not know quite a lot about what is happening in their minds. It seems fair to ask skeptics to do more than say 'as if' is not enough' and to assume some responsibility for studying these questions in more rigorous ways (Bekoff 2000b).

In Species of Mind, Allen and Bekoff (1997) argued that there are a number of reasons that cognitive explanations that entail beliefs, desires, or intentions may be the best explanations to which to appeal because they help us come to terms with questions centering on the comparative and evolutionary study of animal minds. First, the explanatory power of our theorizing is increased. Second, it is obvious that a cognitive approach can generate new ideas that can be tested empirically, help in evaluations of extant explanations, lead to the development of new predictive models, and perhaps, lead to the reconsideration of old data, some of which might have resisted explanation without a cognitive perspective. Third, cognitive explanations account for observed flexibility in behavior better than do less flexible stimulusresponse accounts that stipulate do 'this' in 'this' situation or 'that' in 'that' situation (Bekoff 1996). Fourth, cognitive explanations might help scientists come to terms with larger sets of available data that are 
difficult to understand. Fifth, cognitive explanations may also be more parsimonious and less cumbersome than explanations that require numerous and diverse stimulus-response contingencies (Bekoff 1996; Allen and Bekoff 1997; Bekoff and Allen 1997; see also (de Waal 1991).

The ability to predict what an individual is likely to do next in a social encounter might be a useful litmus test for what is happening in that individual's brain. This is not to say that the ability to predict on-going behavior will ever be as accurate as, say, astronomical predictions concerning the position of stars in the sky. Nonetheless, researchers and others who have spent much time watching individual animals are rather good at predicting their behavior, and many of these predictions are tied in with attributions of beliefs, desires, or intentions. This is the case for my own extensive experience of watching canids signal their intentions to engage in and to maintain social play. Intentional or representational explanations are important to my making accurate predictions about future behavior.

All I want to put out on the table here is the idea that the ability to predict behavior with a high degree of accuracy might also be a good reason to favor cognitive explanations in certain situations. Accurate prediction might be used as one measure of what a human observer 'knows' about the behavior of the animals he or she is studying.

\section{There is Wild Justice, fairness, and social cooperation: Doing what comes naturally}

Justice presumes a personal concern for others. It is first of all a sense, not a rational or social construction, and I want to argue that this sense is, in an important sense, natural. (Solomon 1995, p. 102).

It is not difficult to imagine the emergence of justice and honor out of the practices of cooperation. (Damasio 2003, p. 162).

More than any other species, we are beneficiaries and victims of a wealth of emotional experience. (Dolan 2002, 1191).

Our evaluative conceptions from the nature and ideals of right-living are drawn from vast networks of social activities that have transpired over enormous reaches of time: models of conduct and character have been established, assayed, rejected, confirmed, revised, redrawn, shown unfit. (Hudson 1986, p. 121).

To learn more about the evolution of cognitive capacities and morality we need to broaden our taxonomic studies to include species other than nonhuman primates. We need to go beyond primatocentrism which usually is 'great ape-o-centrism' (see also Keeley this volume). Some authors have been more resistant to this idea than others. Consider the following claims by the Richard Byrne (1995, my emphases added) from his book The Thinking Ape.

It seems that the great apes, especially the common chimpanzee, can attribute mental states to other individuals; but no other group of animals can do so - apart from ourselves, and perhaps cetaceans. (p. 146) This contrasts with the findings on understanding of beliefs, attribution of intentions, and how things work - where a sharp discontinuity is implied between great apes and all other animals. (p. 154)

Of course, until similar painstaking work is done with monkeys, we cannot argue that only apes have such abilities... and no-one has yet risked the huge expenditure of time and money to find out. (p. 172) 
We simply do not have enough data to make hard and fast claims about the taxonomic distribution among different species of the cognitive skills and emotional capacities necessary for being able to empathize with others, to behave fairly, or to be moral agents. Marler (1996, p. 22) concluded a review of social cognition in non-human primates and birds as follows: 'I am driven to conclude, at least provisionally, that there are more similarities than differences between birds and primates. Each taxon has significant advantages that the other lacks.' Tomasello and Call 1997, pp. 399-400) summarized their comprehensive review of primate cognition by noting that 'The experimental foundation for claims that apes are 'more intelligent' than monkeys is not a solid one, and there are few if any naturalistic observations that would substantiate such broad-based, species-general claims.' While Flack and de Waal's (2000) and others' focus is on non-human primates as the most likely animals to show precursors to human morality, others have argued that we might learn as much or more about the evolution of human social behavior by studying social carnivores (Schaller and Lowther 1969; Tinbergen 1972; Thompson 1975; Drea and Frank 2003), species whose social behavior and organization resemble that of early hominids in a number of ways (divisions of labor, food sharing, care of young, and inter- and intrasexual dominance hierarchies).

What we really need are long-term field studies of social animals for which it would be reasonable to hypothesize that emotions and morality have played a role in the evolution of sociality, that emotions and morality are important in the development and maintenance of social bonds that allow individuals to work together for the benefit of all group members (see also Gruen 2002).

To stimulate further comparative research (and the development of models) on a wider array of species than has previously been studied, I offer the hypothesis that social morality, in this case behaving fairly, is an adaptation that is shared by many mammals, not only by non-human and human primates. Behaving fairly evolved because it helped young animals acquire social (and other) skills needed as they mature into adults. A focus on social cooperation is needed to balance the plethora of research that is devoted to social competition and selfishness (for further discussion see Boehm 1999; Singer 1999; Wilson 2002).

I also wonder if our view of the world would have been different had Charles Darwin been a female, if some or many of the instances in which competition is invoked were viewed as cooperation. Women tend to 'see' more cooperation in nature than do men. Adams and Burnett (1991) discovered that female ethologists working in East Africa use a substantially different descriptive vocabulary than do male ethologists. Of the nine variables they studied, those concerning cooperation and female gender were the most important discriminating women's and men's word use. They concluded (p. 558) that 'The variable COOPERATION demonstrates the appropriateness of feminist claims to connection and cooperation as women's models for behavior, as divergent from the traditional competitive model.' Why women and men approach the same subject from a different perspective remains largely unanswered. Perhaps there is more cooperation than meets the eye.

Group-living animals in which there is a variety of complex social interactions among individuals and in which individuals assess social relationships may provide many insights into animal morality (Bekoff 2002a,b, 2003b; Drea and Frank 2003). In many social groups individuals establish social hierarchies and develop and maintain tight social bonds that help to regulate social behavior. Individuals coordinate their behavior - some mate, some hunt, some defend resources, some accept subordinate status - to achieve common goals and to maintain social stability. Consider briefly, pack-living wolves, exemplars of highly developed cooperative and coordinated behavior. Solomon (1995, pp. 139ff) also considers the importance of learning more about wolves in his discussion of justice, emotions, and the origins of social contracts.) 
For a long time researchers thought pack size was regulated by available food resources. Wolves typically feed on such prey as elk and moose, each of which is larger than an individual wolf. Hunting such large ungulates successfully takes more than one wolf, so it made sense to postulate that wolf packs evolved because of the size of wolves' prey. Defending food might also be associated with packliving. However, long-term research by (Mech 1970) showed that pack size in wolves was regulated by social and not food-related factors. Mech discovered that the number of wolves who could live together in a coordinated pack was governed by the number of wolves with whom individuals could closely bond ('social attraction factor') balanced against the number of individuals from whom an individual could tolerate competition ('social competition factor'). Codes of conduct and packs broke down when there were too many wolves. (Colin Allen, personal communication, notes that it is possible that social factors might be proximate influences after long periods of selection for hunting prey of a certain size favoring packs of a certain size.) Whether or not the dissolution of packs was due to individuals behaving unfairly is unknown, but this would be a valuable topic for future research in wolves and other social animals. Solomon (1995, p. 143) contends that 'A wolf who is generous can expect generosity in return. A wolf who violates another's ownership zone can expect to be punished, perhaps ferociously, by others.' These claims can easily be studied empirically. (For interesting studies of the 'social complexity hypothesis' that claims 'that animals living in large social groups should display enhanced cognitive abilities' when compared to those who do not, see Bond et al. (2003 p. 479) and Drea and Frank (2003).

In social groups, individuals often learn what they can and cannot do, and the group's integrity depends upon individuals agreeing that certain rules regulate their behavior. At any given moment individuals know their place or role and that of other group members. As a result of lessons in social cognition and empathy that are offered in social play, individuals learn what is 'right' or 'wrong' - what is acceptable to others - the result of which is the development and maintenance of a social group that operates efficiently. The absence of social structure and boundaries can produce gaps in morality that lead to the dissolution of a group (Bruce Gottlieb, personal communication).

In summary, I argue that mammalian social play is a useful behavioral phenotype on which to concentrate in order to learn more about the evolution of fairness and social morality. (While birds and individuals of other species engage in social play, there are too few data from which to draw detailed conclusions about the nature of their play.) There is strong selection for playing fairly because most if not all individuals benefit from adopting this behavioral strategy (and group stability may be also be fostered). Numerous mechanisms (play invitation signals, variations in the sequencing of actions performed during play when compared to other contexts, self-handicapping, role-reversing) have evolved to facilitate the initiation and maintenance of social play in numerous mammals - to keep others engaged - so that agreeing to play fairly and the resulting benefits of doing so can be readily achieved.

Ridley (1996) points out that humans seem to be inordinately upset about unfairness, but we do not know much about others animals reaction to unfairness. He suggests that perhaps behaving fairly pays off in the long run. Brosnan and de Waal, (2003) have recently shown that captive brown capuchin monkeys who were trained to exchange a token for cucumber would no longer do so when they saw another monkey receive a grape, a more favored reward. The monkey's response to unequal reward distribution was interpreted as their having a sense of fairness. Dugatkin's and my model of the development and evolution of cooperation and fairness (Dugatkin and Bekoff 2003) suggests it might. Hauser (2000) concluded that there is no evidence that animals can evaluate whether an act of reciprocation is fair. However, he did not consider social play in his discussion of animal morality and moral agency. de Waal (1996) remains skeptical about the widespread taxonomic distribution of cognitive empathy after briefly considering social play, but he remains open to the possibility that cognitive empathy might be found in animals other than the great apes (see Preston and de Wall 2002). It is premature to dismiss the 
possibility that social play plays some role in the evolution of fairness and social morality or that animals other than primates are unable intentionally to choose to behave fairly because they lack the necessary cognitive skills or emotional capacities. We really have very little information that bears on these questions.

Let me emphasize again that I am not arguing that there is a gene for fair or moral behavior. As with any behavioral trait, the underlying genetics is bound to be complex, and environmental influences may be large and difficult to pin down. Nonetheless, provided there is variation in levels of morality among individuals and the trait is highly heritable, and provided virtue is rewarded by a greater number of offspring, then genes associated with good behavior are likely to accumulate in subsequent generations. The observation that play is rarely unfair or uncooperative is surely an indication that natural selection acts to weed out those individuals who do not play by the rules.

Future comparative research that considers the nature and details of the social exchanges that are needed for animals to engage in play - reciprocity and cooperation - will undoubtedly produce data that bear on the questions that I raise in this brief essay and also help to 'operationalize' the notion of behaving fairly by informing us about what sorts of evidence confirm that animals are behaving with some sense of fairness. In the absence of this information it is premature to dismiss the possibility that social play plays some role in the evolution of fairness and social morality or that animals other than primates are unable intentionally to choose to behave fairly because they lack the necessary cognitive skills or emotional capacities. These are empirical questions for which the comparative data base is scant.

Gruen (2002) also correctly points out that we still need to come to terms with what it means to be moral. She also suggests that we need to find out what cognitive and emotional capacities operate when humans perform various moral actions, and to study animals to determine if they share these capacities or some variation of them. Even if it were the case that available data suggested that non-human primates do not seem to behave in a specific way, for example, playing fairly, in the absence of comparative data this does not justify the claim that individuals of other taxa cannot play fairly. (At a meeting in Chicago, Illinois in August 2000 dealing with social organization and social complexity (see de Waal and Tyack 2003), it was hinted to me that while my ideas about social morality are interesting, there really is no way that social carnivores could be said to be so decent - to behave (play) fairly - because it was unlikely that even non-human primates were this virtuous.)

Learning about the taxonomic distribution of animal morality involves answering numerous and often difficult questions. Perhaps it will turn out that the best explanation for existing data in some taxa is that some individuals do indeed on some occasions modify their behavior to play fairly.

Play may be a unique category of behavior in that asymmetries are tolerated more so than in other social contexts. Play cannot occur if the individuals choose not to engage in the activity and the equality (or symmetry and kindness) needed for play to continue makes it different from other forms of seemingly cooperative behavior (e.g. hunting, care-giving). This sort of egalitarianism is thought to be a precondition for the evolution of social morality in humans. From whence did it arise? Truth be told, we really do not know much about the origins of egalitarianism. Arm-chair discussions, while important, will do little in comparison to our having direct experiences with other animals. In my view, studies of the evolution of social morality are among the most exciting and challenging projects that behavioral scientists (ethologists, geneticists, evolutionary biologists, neurobiologists, psychologists, anthropologists), theologians, and religious scholars face. We need to rise to the extremely challenging (and frustrating) task before us rather than dismiss summarily and unfairly, in a speciesistic manner, the moral lives of other animals. Fair is fair. 


\section{Morality and human nature: the precautionary principle}

Just what role does human morality play in defining 'human nature'? We do not really know despite strong claims to the contrary. Using animal models to rationalize cruelty, divisiveness, warfare, territoriality, and selfishness, is a disingenuous use of much available information on animal social behavior. While animals surely can be nasty this does not explain much of the behavior that is expressed to other individuals. I have argued that animals make choices to be nice and to be fair.

Ecologists and environmentalists have developed what they call the 'precautionary principle' that is used for making decisions about environmental problems. This principle states that a lack of full scientific certainty should not be used as an excuse to delay taking action on some issue. The precautionary principle can be easily applied in studies of the evolution of social morality. To wit, I claim that we know enough to warrant further comparative studies of the evolution of social morality in animals other than non-human primates, and that until these data are available we should keep an open mind about what individuals of other taxa can and cannot do.

It is important for us to learn more about the evolution of social morality and how this information can be used to give us hope for the future rather than our accepting a dooms-day view of where we are all heading 'because it's in our nature.' Accepting that competition, selfishness, and cheating are what drives human and animal behavior leaves out a lot of the puzzle of how we came to be who we are. Cooperation and fairness can also be driving forces in the evolution of sociality.

The importance of interdisciplinary collaboration and cooperation in studies of animal cognition, cooperation, and moral behavior cannot be emphasized too strongly. It is clear that morality and virtue did not suddenly appear in the evolutionary epic beginning with humans. While fair play in animals may be a rudimentary form of social morality it still could be a forerunner of more complex and more sophisticated human moral systems. It is self-serving anthropocentric speciesism to claim that we are the only moral beings in the animal kingdom. It is also a simplistic and misleading view to assume that humans are merely naked apes.

The origins of virtue, egalitarianism, and morality are more ancient that our own species. Humans also are not necessarily morally superior to other animals. But, we will never learn about animal morality if we close the door on the possibility that it exists. It is still far too early to draw the uncompromising conclusion that human morality is different in kind from animal morality and walk away in victory.

\section{Acknowledgments}

Much of this discussion appeared in two of my previous papers (Bekoff 2001a,b) and has been updated where possible. Some of this material is reprinted from The Origins and Nature of Sociality, R. Sussman and A. Chapman, eds., pp. 53-80, Copyright (c) 2004 Walter de Gruyter, Inc. Published by Aldine de Gruyter, Hawthorne, NY. I thank Jan Nystrom, Bob Sussman, and especially Colin Allen and Rob Skipper for comments on an earlier draft of this paper.

\section{References}

Adams E.R. and Burnett G.W. 1991. Scientific vocabulary divergence among female primatologists working in East Africa. Soc. Stud. Sci. 21: 547-560.

Aldis O. 1975. Play Fighting. Academic Press, New York.

Allen C. and Bekoff M. 1997. Species of Mind: The Philosophy and Biology of Cognitive Ethology. MIT Press, Cambridge, Massachusetts. 
Aureli F. and de Waal F.B.M. (ed.) 2000. Natural Conflict Resolution. University of California Press, Berkeley.

Aviles L. 1999. Cooperation and non-linear dynamics: an ecological perspective on the evolution of sociality. Evol. Ecol. Res. 1: 459-477.

Axelrod R. 1984. The Evolution of Cooperation. Basic Books, New York.

Bateson G. 2000. Steps to an Ecology of Mind. University of Chicago Press, Chicago.

Bauer E.B. and Smuts B.B. 2002. Role reversal and self-handicapping during playfighting in domestic dogs, Canis familiaris. Paper presented at the meetings of the Animal Behavior Society. University of Indiana.

Bekoff M. 1975. The communication of play intention: are play signals functional? Semiotica 15: 231-239.

Bekoff M. 1977a. Social communication in canids: evidence for the evolution of a stereotyped mammalian display. Science 197: 1097-1099.

Bekoff M. 1977b. Mammalian dispersal and the ontogeny of individual behavioral phenotypes. Am. Nat. 111: 715-732.

Bekoff M. 1995. Play signals as punctuation: the structure of social play in canids. Behaviour 132: 419429.

Bekoff M. 1996. Cognitive ethology, vigilance, information gathering, and representation: who might know what and why? Behav. Process. 35: 225-237.

Bekoff M. (ed.) 2000a. The Smile of a Dolphin: Remarkable Accounts of Animal Emotions. Discovery Books/Random House, New York.

Bekoff M. 2000b. Animal emotions: exploring passionate natures. BioScience 50: 861-870.

Bekoff M. 2001a. Social play behaviour, cooperation, fairness, trust and the evolution of morality. J. Conscious. Stud. 8(2): 81-90.

Bekoff M. 2001b. The evolution of animal play, emotions, and social morality: on science, theology, spirituality, personhood, and love. Zygon (J. Reli. Sci.) 36: 615-655.

Bekoff M. 2002a. Minding Animals: Awareness, Emotions, and Heart. Oxford University Press, New York.

Bekoff M. 2002b. Virtuous nature. New Scientist 13 July, pp. 34-37.

Bekoff M. 2002c. Self-awareness. Nature 419: 255.

Bekoff M. 2003a. Consciousness and self in animals: some reflections. Zygon (J. Reli. Sci.) 38: 229-245.

Bekoff M. 2003b. Empathy: common sense, science sense, wolves, and well-being. Behav. Brain Sci. 25: $26-27$.

Bekoff M. 2004. The question of animal emotions: an ethological perspective. In: McMillan F. (ed.), Mental Health and Well-being in Animals. Iowa State University Press, Ames, lowa.

Bekoff M. (in press). Wild Justice and Fair Play: Cooperation, Forgiveness and Morality in Animals. University of Chicago Press, Chicago.

Bekoff M. and Allen C. 1992. Intentional icons: towards an evolutionary cognitive ethology. Ethology 91: 1-16.

Bekoff M. and Allen C. 1997. Cognitive ethology: slayers, skeptics, and proponents. In: Mitchell R.W., Thompson N. and Miles L. (eds), Anthropomorphism, Anecdote, and Animals: The Emperor's New Clothes? SUNY Press, Albany, New York, pp 313-334.

Bekoff M. and Allen C. 1998. Intentional communication and social play: how and why animals negotiate and agree to play. In: Bekoff M. and Byers J.A. (ed.), Animal Play: Evolutionary, Comparative, and Ecological Perspectives. Cambridge University Press, Cambridge and New York, pp. 97114.

Bekoff M., Allen C. and Burghardt G.M. (eds), 2002. The Cognitive Animal. MIT Press, Cambridge, Massachusetts.

Bekoff M. and Byers J.A. 1981. A critical reanalysis of the ontogeny of mammalian social and locomotor play: an ethological hornet's nest. In: Immelmann K., Barlow G.W., Petrinovich L. and Main M. 
(eds), Behavioral Development: The Bielefeld Interdisciplinary Project. Cambridge University Press, New York, pp. 296-337.

Bekoff M. and Byers J.A. (eds), 1998. Animal Play: Evolutionary, Comparative, and Ecological Approaches. Cambridge University Press, New York.

Bekoff M. and Wells M.C. 1986. Social behavior and ecology of coyotes. Adv. Study Behav. 16: 251-338.

Bernstein I.S. 2000. The law of parsimony prevails: missing premises allow any conclusion. J. Conscious. Stud. 7: 31-34.

Bewley T. 2003. Fair's fair. Nature 422: 125-126.

Boehm C. 1999. Hierarchy in the Forest: The Evolution of Egalitarian Behavior. Harvard University Press, Cambridge.

Bond A., Kamil A.C. and Balda R.P. 2003. Social complexity and transitive inference in corvids. Animal Behav. 65: 479-487.

Bowles S. and Gintis H. 2002. Home reciprocans. Nature 415: 125-128.

Bradie M. 1999. Evolutionary game theory meets the social contract. Biol. Philos. 14: 607-613.

Bradley B.J. 1999. Levels of selection, altruism, and primate behavior. Quart. Rev. Biol. 74: 171-194.

Brosnan S.F. and de Waal F.B.M. 2003. Monkeys reject unequal pay. Nature 425: 297-299.

Burghardt G.M. 1997. Amending Tinbergen: A fifth aim for ethology. In: Thomson Mitchell R.W.N. and Miles L. (eds), Anthropomorphism, Anecdote, and Animals: The Emperor's New clothes? SUNY Press, Albany (NY), pp. 254-276.

Burghardt G.M. 2005. The Genesis of Play. MIT Press, Cambridge, Massachusetts.

Byers J.A. 1977. Terrain preferences in the play of Siberian ibex kids (Capra ibex sibirica). Zeitschrift für Tierpsychologie 45: 199-209.

Byers J.A. 1998. Biological effects of locomotor play: getting into shape or something else. In: Bekoff M. and Byers J.A. (eds), Animal Play: Evolutionary, Comparative, and Ecological Perspectives. Cambridge University Press, New York, pp. 205-220.

Church F. 1959. Emotional reactions of rats to the pain of others. J. Compar. Physiol. Psychol. 52: 132134.

Damasio A. 2003. Looking for Spinoza: Joy, Sorrow, and the Feeling Brain. Harcourt, New York.

Darwin C. 1859. On the Origin of Species By Means of Natural Selection. Murray, London.

Darwin C. 1871/1936. The Descent of Man and Selection in Relation to Sex. Random House, New York.

Darwin C. 1872/1998. The Expression of the Emotions in Man and Animals, 3rd ed. Oxford University Press, New York, (with an Introduction, Afterword, and Commentaries by Paul Ekman).

Dawkins R. 1976. The Selfish Gene. Oxford University Press, New York.

Dawkins R. 2001. Sustainability doesn't come naturally: a Darwinian perspective on values. www.environmentfoundation.net/richard-dawkins.htm.

de Waal F. 1991. Complementary methods and convergent evidence in the study of primate social cognition. Behaviour 18: 297-320.

de Waal F. 2001. The Ape and the Sushi Master: Cultural Reflections of a Primatologist. Basic Books, New York.

de Waal F. and Tyack P.L. (eds), 2003. Animal Social Complexity: Intelligence, Culture, and Individualized Societies. Harvard University Press, Cambridge, Massachusetts.

Dolan R.J. Emotion, cognition, and behavior. 2002. Science 298: 1191-1194.

Douglas K. 2001. Playing fair. New Scientist 10 March (No. 2281). pp. 38-42.

Drea C.M. and Frank L.G. 2003. The social complexity of spotted hyenas. In: de Waal F. and Tyack P.L. (eds), Animal Social Complexity: Intelligence, Culture, and Individualized Societies. Harvard University Press, Cambridge, Massachusetts, pp. 121-148.

Dugatkin L.A. 1997. Cooperation Among Animals: An Evolutionary Perspective. Oxford University Press, New York. 
Dugatkin L.A. and Bekoff M. 2003. Play and the evolution of fairness: a game theory model. Behav. Proc. 60: 209-214.

Dylan B. 1983. Infidels. CBS Inc.

Fagen R. 1981. Animal Play Behavior. Oxford University Press, New York.

Fagen R. 1993. Primate juveniles and primate play. In: Pereira M.E. and Fairbanks L.A. (eds), Juvenile Primates: Life History, Development, and Behavior. Oxford University Press, New York pp. 183196.

Fehr E. and Gächter S. 2002. Altruistic punishment in humans. Nature 415: 137-140.

Fehr E. and Rockenbach B. 2003. Detrimental effect of sanctions on human altruism. Nature 422: 137140.

Field A. 2001. Altruistically Inclined? The Behavioral Sciences, Evolutionary Theory, and the Origins of Reciprocity. The University of Michigan Press, Ann Arbor.

Flack J.C. and de Waal F. 2000. Any animal whatever: Darwinian building blocks of morality in monkeys and apes. J. Conscious. Stud. 7: 1-29.

Flack J.C., Jeannotte L.A. and de Waal F. 2004. Play signaling and the perception of social rules by juvenile chimpanzees. J. Compar. Psychol, 118: 149-159.

Frith C.D. and Frith U. 1999. Interacting minds - a biological basis. Science 286: 1692-1695.

Gallese V. 1998. Mirror neurons, from grasping to language. Conscious. Bull. Fall 3-4.

Gallese V. and Goldman A. 1998. Mirror neurons and the simulation theory of mind-reading. Trends Cogn. Sci. 2: 493-501.

Gould S.J. and Lloyd E.A. 1999. Individuality and adaptation across levels of selection: how shall we name and generalize the unit of Darwinism. Proc. Natl. Acad. Sci. 96: 11904-11909.

Griffin D.R. 2001. Animal Minds. University of Chicago Press, Chicago.

Gruen L. 2002. The morals of animal minds. In: Bekoff, Allen and Burghardt (eds), The Cognitive Animal, MIT Press, Cambridge, Massachusetts, pp. 437-442.

Güzeldere G. and Nahmias E. 2002. Darwin's continuum and the building blocks of deception. In: Bekoff , Allen and Burghardt (eds), The Cognitive Animal, MIT Press, Cambridge, Massachusetts, pp. 353-362.

Hauser M. 2000. Wild Minds. Henry Holt, New York.

Hill H.L. and Bekoff M. 1977. The variability of some motor components of social play and agonistic behaviour in Eastern coyotes. Canis latrans var Animal Behav. 25: 907-909.

Hinde R.A. 2002. Why Good is Good: The Sources of Morality. Routledge, New York.

Dalai Lama 2002. Understanding our fundamental nature. In: Davidson R.J. and Harrington A. (eds), Visions of Compassion: Western Scientists and Tibetan Buddhists Examine Human Nature. Oxford University Press, New York, pp. 66-80.

Horowitz A.C. 2002. The behaviors of theories of mind, and a case study of dogs at play. Ph.D. dissertation, University of California, San Diego.

Hudson S.D. 1986. Human Character and Morality: Reflections from the History of Ideas. Routledge \& Kegan Paul, Boston.

Hurd J.P. 1996. (ed). Investigating the Biological Foundations of Human Morality. The Edwin Mellen Press, Lewiston, New York.

Jamieson D. 2002. Sober and Wilson on psychological altruism. Philos. Phenomenol. Res.. LXV: 702710.

Jamieson D. and Bekoff M. 1993. On aims and methods of cognitive ethology. Philosophy of Science Association 2: 110-124.

Kitchen D.M. and Packer C. 1999. Complexity in vertebrate societies. In: Keller L. (ed.), Levels of Selection in Evolution. Princeton University Press, Princeton, New Jersey, pp. 176-196.

Kropotkin P. 1902. Mutual aid: a factor of evolution. Philips \& Co, McClure, New York. 
Kuczaj S., Tranel K., Trone M. and Hill H. 2001. Are animals capable of deception or empathy? Implications for animal consciousness and animal welfare. Animal Welfare 10: S161-173.

Leigh E.G. Jr. 1999. Levels of selection, potential conflicts, and their resolution: Role of the "Common good". In: Keller L. (ed.), Levels of Selection in Evolution. Princeton University Press, Princeton, New Jersey, pp. 15-30.

Macintyre A. 1999. Dependent Rational Animals: Why Human Beings Need the Virtues. Open Court, Chicago.

Markowitz H. 1982. Behavioral Enrichment in the Zoo. Van Reinhold Company, New York.

Marler P. 1996. Social cognition: are primates smarter than birds? In: Nolan V. Jr. and Ketterson E.D. (eds), Current Ornithology, Vol. 13. Plenum Press, New York, pp. 1-32.

Mayr E. 2000. Darwin's influence on modern thought. Sci. Am. 283: 67-71.

Mech L.D. 1970. The Wolf. Garden City, Doubleday, New York.

Mitchell L.E. 1998. Stacked Deck: A Story of Selfishness in America. Temple University Press, Philadelphia, Pennsylvania.

Motluk A. 2001. Read my mind. New Sci. 169: 22-26.

Neuman Y. 2003. The logic of meaning-in-context. Am. J. Semiotics (special issue: Gregory Bateson).

Okamoto K. and Matsumara S. 2000. The evolution of punishment and apology: an iterated prisoner's dilemma model. Evol. Ecol. 14: 703-720.

Poole J. 1998. An exploration of a commonality between ourselves and elephants. Etica Animali 9/98: 85-110.

Panksepp J. 1998. Affective Neuroscience. Oxford University Press, New York.

Panksepp J. 2000. The rat will play. In: Bekoff M. (ed.), The Smile of a Dolphin: Remarkable Accounts of Animal Emotions. Random House/Discovery Books, New York, pp. 146-147.

Pellis S. 2002. Keeping in touch: play fighting and social knowledge. In: Bekoff, Allen and Burghardt (eds), The Cognitive Animal, MIT Press, Cambridge, Massachusetts, pp. 421-427.

Peterson G.R. 1999. The evolution of consciousness and the theology of nature. Zygon 34: 283-306.

Peterson G.R. 2000. God, genes, and cognizing agents. Zygon 35: 469-480.

Pigliucci M. 2002. Are ecology and evolutionary biology "soft" sciences? Ann. Zool. Fenn. 39: 87-98.

Power T.G. 2000. Play and Exploration in Children and Animals. Lawrence Erlbaum Associates, Hillsdale, New Jersey.

Preston S.D. and de Waal F.B.M. 2002. Empathy: its ultimate and proximate bases. Behav. Brain Sci. 25: $1-72$.

Ridley M. 1996. The Origins of Virtue: Human Instincts and the Evolution of Cooperation. Viking, New York.

Ridley M. 2001. The Cooperative Gene. The Free Press, New York.

Rilling J.K., Gutman D.A., Zeh T.R., Pagnoni G., Berns G.S. and Kitts C.D. 2002. A neural basis for cooperation. Neuron 36: 395-405.

Riolo R.L., Cohen M.D. and Zelrod R. 2001. Evolution of cooperation without reciprocity. Nature 414: 441-443.

Schaller G.B. and Lowther G.R. 1969. The relevance of carnivore behavior to the study of early hominids. Southwestern J. Anthropol. 25: 307-341.

Scott J.P. and Fuller J.L. 1965. Genetics and the Social Behavior of the Dogs. University of Chicago Press, Chicago, Illinois.

Sigmund K., Fehr E. and Nowak M.A. 2002. The economics of fair play. Sci. Am. 286(1): 83-87.

Sigmund K. and Nowak M.A. 2001. Evolution: tides of tolerance. Nature 414: 403-405.

Singer P. 1999. A Darwinian Left: Politics, Evolution, and Cooperation. Yale University Press, New Haven. 
Siviy S. 1998. Neurobiological substrates of play behavior: Glimpses into the structure and function of mammalian playfulness. In: Bekoff M. and Byers J.A. (eds), Animal Play: Evolutionary, Comparative, and Ecological Perspectives. Cambridge University Press, New York, 221-242.

Skyrms B. 1996. Evolution of the Social Contract. Cambridge University Press, New York.

Smuts B.B. 2001. Encounters with animal minds. J. Conscious. Stud. 8: 293-309.

Sober E. and Wilson D.S. 1998. Unto Others: The Evolution and Psychology of Unselfish Behavior. Harvard University Press, Cambridge, Massachusetts.

Sober E. and Wilson D.S. 2000. Summary of: unto others: the evolution and psychology of unselfish behavior. J. Conscious. Stud. 7: 185-206.

Solomon R. 1995. A passion for justice: Emotions and the origins of the social contract. Rowman \& Littlefield Publishers, Inc, Lanham, Maryland.

Spinka M., Newberry R.C. and Bekoff M. 2000. Mammalian play: training for the unexpected. Quart. Rev. Biol. 76: 141-168.

Thompson P.R. 1975. A cross-species analysis of carnivore, primate, and hominid behavior. J. Human Evol. 4: 113-124.

Tinbergen N. 1972. Introduction to Hans Kruuk, The Spotted Hyena. University of Chicago Press, Chicago.

Tomasello M. and Call J. 1997. Primate Cognition. Oxford University Press, New York.

de Waal F. 1996. Good-natured: The Origins of Right and Wrong in Humans and other Animals. Harvard University Press, Cambridge, Massachusetts.

Watson D.M. and Croft D.B. 1996. Age-related differences in playfighting strategies of captive male rednecked wallabies (Macropus rufogriseus banksianus). Ethology 102: 33-346.

Wechlin S., Masserman J.H. and Terris W. Jr. 1964. Shock to a conspecific as an aversive stimulus. Psychon. Sci. 1: 17-18.

Wilson D.S. 2002. Darwin's Cathedral: Evolution, Religion, and the Nature of Society. University of Chicago Press, Chicago.

Wrangham R. and Conklin-Brittain N. 2003. Cooking as a biological trait. Compar. Biochem. Physiol., Part A, 136: 35-46. 